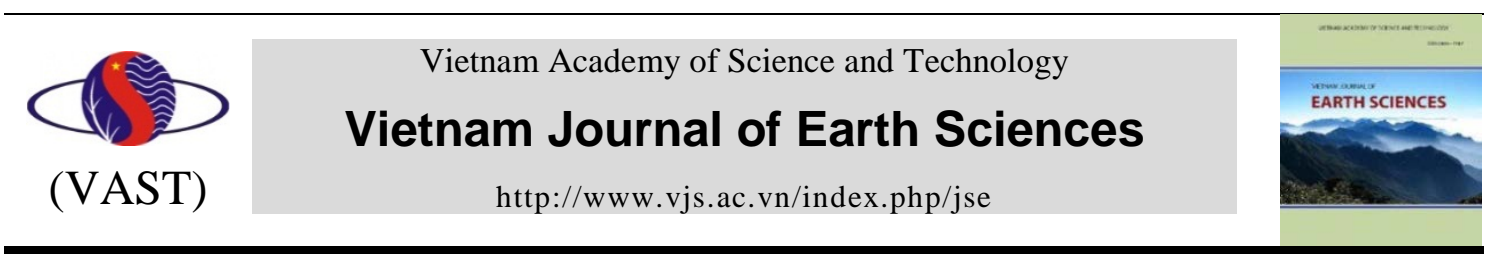

\title{
Correlation and high-resolution timing for Paleo-tethys Permian-Triassic boundary exposures in Vietnam and Slovenia using geochemical, geophysical and biostratigra- phyc data sets
}

Luu Thi Phuong Lan1, Ellwood, Brooks B.2, Tomkin, J onathan H. ${ }^{3}$, Nestell, Galina P.4, Nestell, Merlynd K.4, Ratcliffe, Kenneth T.5, Rowe, Harry 6, Dang Tran Huyen7, Nguyen Thanh Dung', Nguyen Chien Thang ${ }^{1}$, Nguyen Ha Thanh ${ }^{1}$, Dao Van Quyen ${ }^{1}$

${ }^{1}$ Institute of Geophysics (VAST), Hanoi, Vietnam

${ }^{2}$ Department of Geology and Geophysics, Louisiana State University, USA

${ }^{3}$ School of Earth, Society, and Environment, University of Illinois, USA

${ }^{4}$ Department of Earth and Environmental Sciences, University of Texas at Arlington, USA

${ }^{6}$ Bureau of Economic Geology, The University of Texas at Austin, University Station, USA

${ }^{7}$ Geological Society of Vietnam

Received 25 January 2018; Received in revised form 21 May 2018; Accepted 05 June 2018

\section{ABSTRACT}

Two Permian-Triassic boundary (PTB) successions, Lung Cam in Vietnam, and Lukač in Slovenia, have been sampled for high-resolution magnetic susceptibility, stable isotope and elemental chemistry, and biostratigraphic analyses. These successions are located on the eastern (Lung Cam section) and western margins (Lukač section) of the Paleo-Tethys Ocean during PTB time. Lung Cam, lying along the eastern margin of the Paleo-Tethys Ocean provides an excellent proxy for correlation back to the GSSP and out to other Paleo-Tethyan successions. This proxy is tested herein by correlating the Lung Cam section in Vietnam to the Lukač section in Slovenia, which was deposited along the western margin of the Paleo-Tethys Ocean during the PTB interval. It is shown herein that both the Lung Cam and Lukač sections can be correlated and exhibit similar characteristics through the PTB interval. Using timeseries analysis of magnetic susceptibility data, high-resolution ages are obtained for both successions, thus allowing relative ages, relative to the PTB age at $\sim 252 \mathrm{Ma}$, to be assigned. Evaluation of climate variability along the western and eastern margins of the Paleo-Tethys Ocean through the PTB interval, using $\delta^{18} \mathrm{O}$ values indicates generally cooler climate in the west, below the PTB, changing to generally warmer climates above the boundary. A unique Black Carbon layer (elemental carbon present by agglutinated foraminifers in their test) below the boundary exhibits colder temperatures in the eastern and warmer temperatures in the western Paleo-Tethys Ocean.

Keywords: Permian-Triassic boundary; Vietnam; Slovenia; time-series analysis; Black Carbon; magnetostratigraphy susceptibility; Hindeodus parvus.

(C)2018 Vietnam Academy of Science and Technology

\section{Introduction}

Our understanding of the timing of events

"Corresponding author, Email: luuphuonglan@gmail.com in Earth history is seriously hampered by age uncertainties for most of geologic time. This problem becomes critically important in resolving the timing of significant events. It is 
possible that age uncertainties have actually 'created' distinctive changes in Earth history, or the importance of some changes have been missed because abrupt changes are not correctly identified within globally distributed stratigraphic sequences, or changes are thought to be different in age, when in fact they are coeval. When looking at geological boundary successions and developing data sets that are useful for global geological interpretations, it is very important that the boundary of interest is known with only small uncertainty. Because critical events recorded in stratigraphic successions can easily be missed, if sampling is too coarse or if the boundary level is misidentified, tools to establish position in time are critical in modern geological research.

The Global Boundary Stratotype Section and Point (GSSP) for the base of the Triassic is located at the Meishan Section D in China, and is based on the First Appearance Datum (FAD) at the GSSP of the conodont Hindeodus parvus. This precise stratigraphic point now defines the position in time of the Permian-Triassic boundary (PTB). Elsewhere, $H$. parvus may appear earlier or later, and therefore Ellwood et al. (2017) have argued that other than at the GSSP section, rather than the term FAD, the Lowest Observed Occurrence Point (LOOP) should be used in identifying the lowest appearance of $H$. parvus. These authors used the Graphic Correlation method (Shaw, 1964) to compare the Meishan D PTB section to the Lung Cam section in Vietnam, and showed that the LOOP of $H$. parvus at Lung Cam lies at a level $\sim 0.8+/-0.1 \mathrm{~m}$ below the FAD as defined at the GSSP. In addition, the extinction levels in Beds 10/11 and ash Bed 13 at Lung Cam are well correlated to the Meishan GSSP. The results of this work has allowed development of hi-resolution relative timing for deposition of the strata of the Lung Cam section, using time-series analysis of magnetic susceptibility $(\chi)$ data for the PTB interval in Vietnam (Figure 1), where timing is essentially the same as that developed using radiometric methods for the Meishan GSSP section (Shen et al., 2011; Chen et al., 2016).

\section{Material and Methods}

\subsection{Magnetostratigraphy susceptibility}

All substances are "susceptible" to becoming magnetized in the presence of an external magnetic field, and initial low-field bulk, mass-specific magnetic susceptibility $(\chi)$ is an indicator of the strength of this transient magnetism. In marine stratigraphic successions, $\chi$ is generally considered to be an indicator of detrital iron-containing paramagnetic and ferrimagnetic grains, mainly ferromagnesian and clay minerals (Bloemendal and deMenocal, 1989; da Silva and Boulvain, 2002, 2005), and can be quickly and easily measured on small friable samples. In the very low inducing, alternating magnetic fields that are generally applied, $\chi$ is largely a function of the concentration and composition of the magnetizable material in a sample.

Low-field magnetic susceptibility, as used in most reported studies, is defined as the ratio of the induced moment $\left(\mathbf{M}_{\mathbf{i}}\right.$ or $\left.\mathbf{J}_{\mathbf{i}}\right)$ to the strength of an applied, very low-intensity magnetic field $\left(\mathbf{H}_{\mathbf{j}}\right)$, where susceptibility is given as

$$
\begin{array}{cc}
\mathbf{J}_{\mathbf{i}}=\chi_{\mathrm{ij}} \mathbf{H}_{\mathbf{j}} \quad \text { (mass-specific) } \\
\text { or } \mathbf{M}_{\mathbf{i}}=\kappa_{\mathrm{ij}} \mathbf{H}_{\mathbf{j}} . \quad \text { (volume-specific) }
\end{array}
$$

In these expressions, magnetic susceptibility in SI units is parameterized as $\kappa$, indicating that the measurement is relative to a one cubic meter volume $\left(\mathrm{m}^{3}\right)$ and therefore is dimensionless; or magnetic susceptibility is parameterized as $\chi$ and indicates measurement relative to a mass of one $\mathrm{kg}$, and is given in units of $\mathrm{m}^{3} / \mathrm{kg}$.

\subsection{Field Sampling}

In the field a section is first cleaned using scrapers and brushes, so that all beds and 
lithologies are well exposed. Highly weathered zones are cleaned by digging, chipping and brushing, and these zones are noted in the field notes for evaluation of possible alteration effects. In the two studies reported herein, samples were collected for $\chi$ and geochemical measurement at $\sim 5 \mathrm{~cm}$ intervals and returned to the laboratory for study. In addition, bulk samples (>1 kg) were collected for biostratigraphic analysis. The results of biostratigraphic analysis have been reported elsewhere in Ellwood et al., 2017 and related papers.

\subsection{Laboratory Measurement of $\chi$}

$\chi$ measurements reported in this paper were performed using the susceptibility bridge at LSU. The bridge is calibrated relative to mass using standard salts reported by Swartzendruber (1992) and CRC Tables. For each group of measurements - each day, laboratory standards are measured and compared to previous measurement to insure that the bridge is performing properly. $\chi$ is reported in terms of sample mass because it is much easier and faster to measure with high precision than is volume, and it is now the standard for $\chi$ measurement. The low-field $\chi$ bridge at LSU can measure diamagnetic samples at least as low as $-4 \times 10^{-9} \mathrm{~m}^{3} / \mathrm{kg}$. This precision is illustrated by two relatively pure calcite samples from a standing speleothem in Carlsbad Caverns National Park, with values of $3.37 \times 10^{-9}$ and $-3.46 \times 10^{-9} \mathrm{~m}^{3} / \mathrm{kg}$ and standard deviations for three measurements of 7.64 $\times 10^{-11}$ and $8.69 \times 10^{-11} \mathrm{~m}^{3} / \mathrm{kg}$, respectively. These samples are used as standards for additional calibration when very weak samples are being measured. Note that in the Lung Cam section (Figure 1), a large proportion of the samples from the lower part of the section, up to $\sim 5.2 \mathrm{~m}$ of section, are diamagnetic, while none of the samples collected from the Lukač section (Figure 3) exhibited diamagnetic values.

\subsection{Time-series analysis}

After detrending the raw data, the spectral power of $\chi$ for the two sections was obtained using both the Multi-taper (MTM) and Fourier Transform (FT) methods. Incidences of statistically significant peaks (at the 90, 95 and 99\% confidence limits) in the resulting spectra are determined by employing the MTM (Ghil et al., 2002), as calculated with the SSAMTM toolkit (Dettinger et al., 1995). A null hypothesis of red noise was assumed (low frequency high power in the spectrum, sloping toward lower values at high frequencies). As this method is prone to producing false positives, the use of statistical significance is limited herein to its role in supporting (or not) the positions of multiple Milankovitch bands within the data set. The positions of these bands are fixed relative to each other, and so a climate forcing mechanism is supported by the spectral analysis when the Milankovitch frequencies are also frequencies of high spectral power. As this approach substitutes space (length along section) for time, non-uniform rates of sedimentation will introduce additional noise into the spectral graph.

The MTM and FT methods are capable of resolving high frequency features in the data. Our approach is to (1) collect closely and uniformly spaced samples in the field, (2) report both FT and MTM and comparing the two, (3) apply confidence limits to the MTM data, and (4) establish a uniform model using bar logs, that can then be compared to the $\chi$ cyclicity as a check on SAR uniformity, or lack thereof. These four elements allow rigorous evaluation of the time-series data sets developed herein. Time-series analyses for the Lung Cam and Lukač sections are presented in Figure 4a, b. 


\section{Lung Cam, Vietnam}

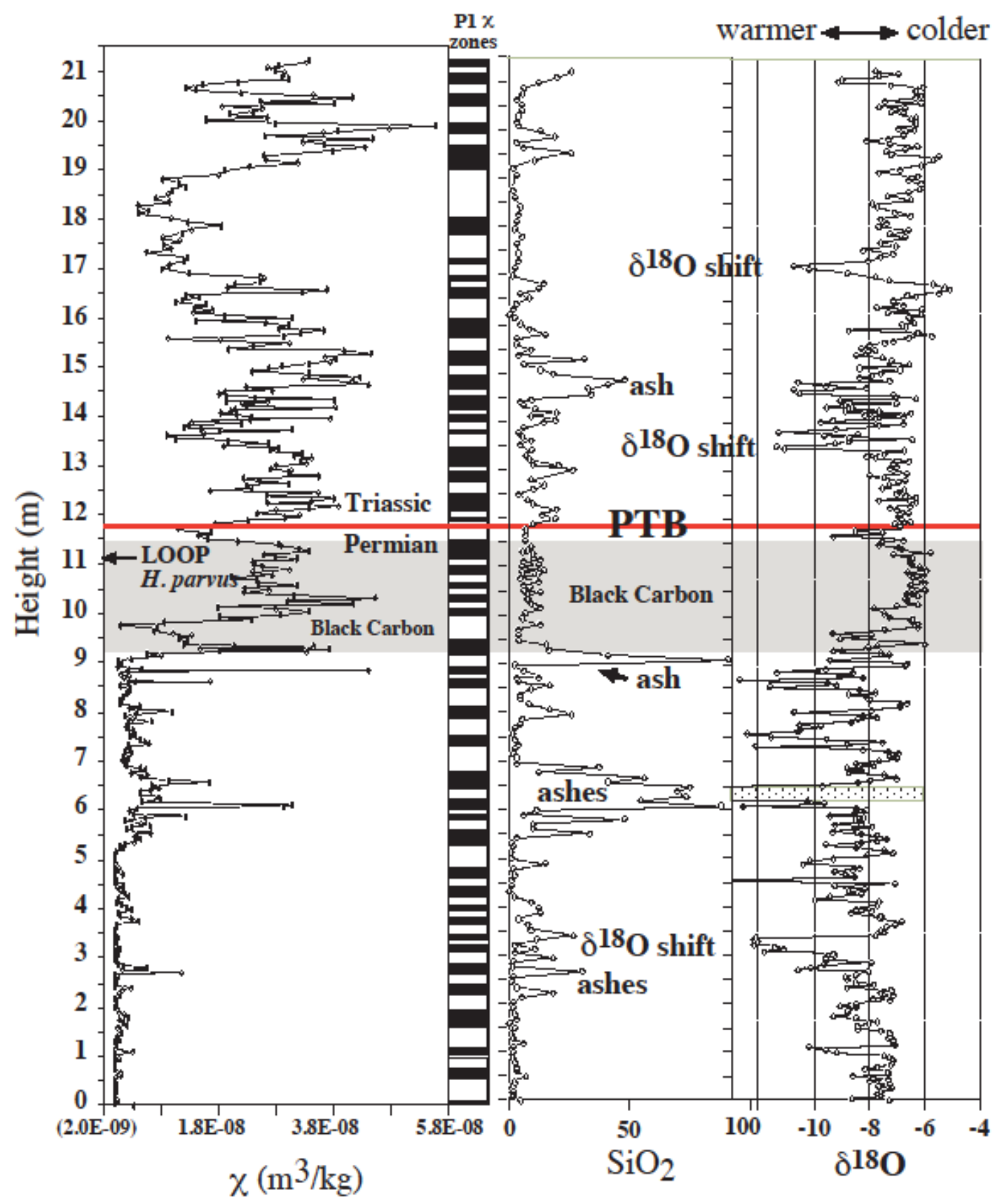

Figure 1. Magnetic susceptibility $(\chi)$, precessional (P1) $\chi$ bar log, lithology log, $\mathrm{SiO}_{2}$ and $\delta^{18} \mathrm{O}$ data with depth ( $\sim 21.23 \mathrm{~m}$ at a $0.05 \mathrm{~m}$ sample interval) through the Lung Cam section, Vietnam, and lithologic log with key beds identified (some of these data are reported in Ellwood, et al., 2017 and referenced papes) in this mainly limestone section and the Black Carbon zone that lies below the boundary herein. There is one zone where there are ankeritic and sideritic components in the limestone 


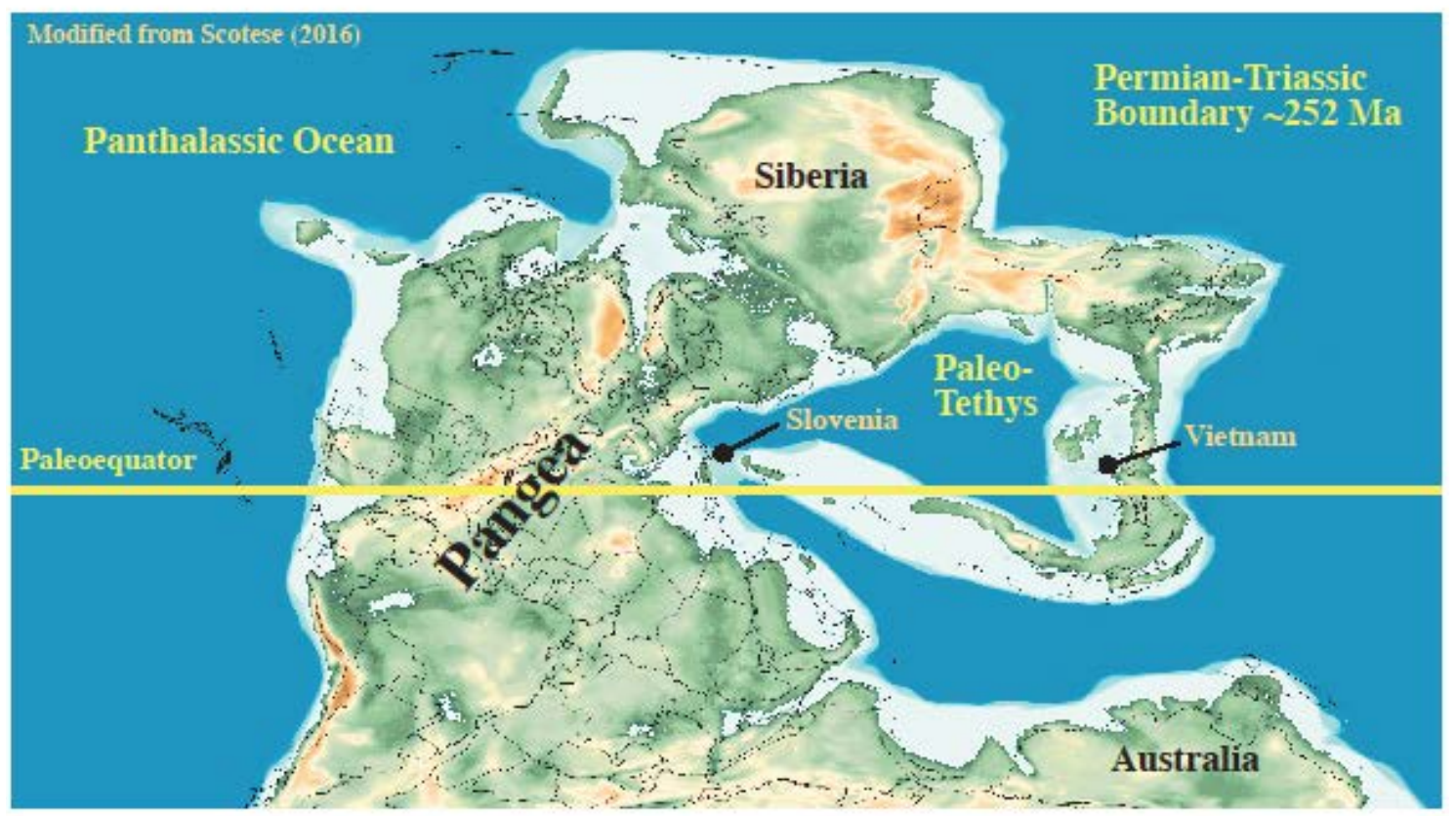

Figure 2. Paleogeographic map for the Permian-Triassic boundary (PTB) at 252 Ma (Scotese, 2001; 2013; 2016, personal communication) and modified by the authors. The location of the studied sections in Vietnam (Lung Cam section; Figure 1) and Slovenia (Lukač section; Figure 3) are identified by the labeled black dots

\subsection{Sample Preparation and Whole-Rock $\mathrm{SiO}_{2}$ and $\delta^{18} \mathrm{O}$ Analyses}

Following the geochemical determination of $\mathrm{SiO}_{2}$ in the samples analyzed, $\sim 0.325 \mathrm{mg}$ of sample was loaded into Exetainer vials, capped and flushed with $\mathrm{He}$, reacted with phosphoric acid, and equilibrated for 13 hours at $50^{\circ} \mathrm{C}$. Stable carbon and oxygen isotopic compositions of the sample were analyzed in continuous flow mode using a ThermoFinnigan Gas Bench II coupled to a Delta V isotope ratio mass spectrometer. Reproducibility (standard deviation) of the in-house standards, NBS-19, NBS-18, and foraminiferal samples, is $0.1 \%$ for $\delta^{18} \mathrm{O}$. Isotopic values are reported with respect to V-PDB.

Stable isotope analysis of carbonate from the Lukač section was performed in the OxyAnion Stable Isotope Consortium (OASIC) at LSU. $200 \pm 20 \mu \mathrm{g}$ carbonate samples were loaded in $12 \mathrm{ml}$ borosilicate glass Exetainer vials (Labco Ltd., Lampeter, UK) and left in oven at $75^{\circ} \mathrm{C}$ for 12 hours. Sample vials were sealed and flushed with $99.999 \%$ He for 2 minutes at a flow rate of $80 \mathrm{ml} /$ minute. Samples were loaded into a 96-position ThermoFinigan Gas Bench II, which was kept at $72^{\circ} \mathrm{C}$. Samples were then acidified with approximately $100 \mu \mathrm{L}$ of concentrated phosphoric acid (density $=1.92 \mathrm{~g} / \mathrm{mL}$ ) by manual injection and kept in an oven at $75^{\circ} \mathrm{C}$. Samples were reacted for 3 hours prior to passage of the $\mathrm{CO}_{2}$ sample stream through a Nafion water trap and GC in the Gas Bench for analysis in the Thermo-Finigan MAT 253 mass spectrometer. One working standard for every 10 samples was measured. The standard is marble calibrated to NBS-19 and LSVEC standards. The $\delta^{18} \mathrm{O}$ of working standard is $-4.31 \%$, (VPDB). The external precision $(1 \sigma)$ is better than $0.1 \%$ for $\delta^{18} \mathrm{O}$, for sample sizes $>200 \mathrm{ug}$. 


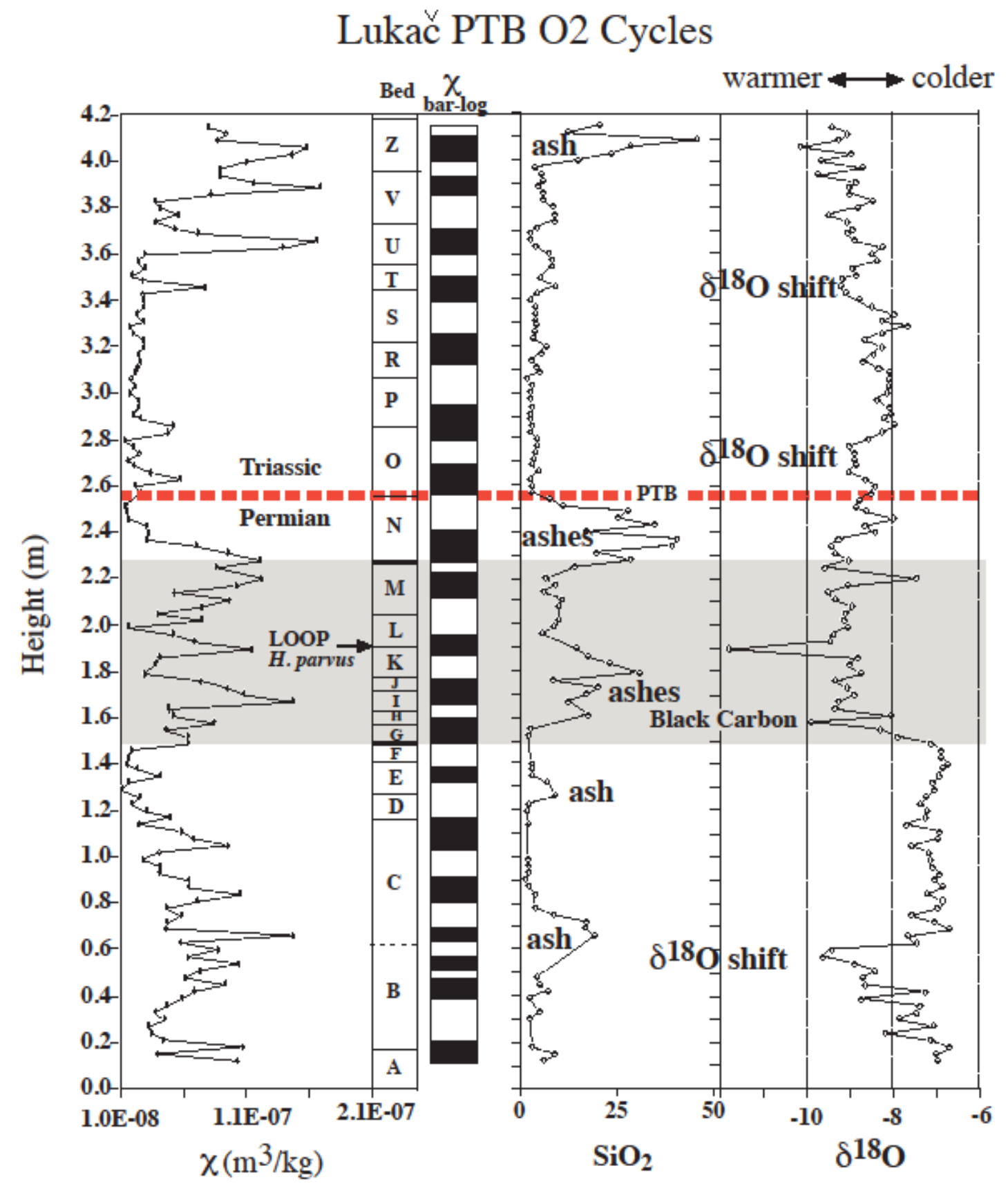

Figure 3. Magnetic susceptibility $(\chi)$, obliquity (O2) $\chi$ bar log, lithology log, $\mathrm{SiO}_{2}$ and $\delta{ }^{18} \mathrm{O}$ data with depth in the Lukač section, Slovenia. Included are the bed and biostratigraphic labels (from Ellwood et al., 2017 and related papers) in this mainly limestone section and the Black Carbon zone that lies below the boundary herein and at Lung Cam (Figure 1). There are two lithologic zones where there are dolomitic, and possibly ankeritic and sideritic components, in the limestone 
Vietnam Journal of Earth Sciences, 40(3), 253-270

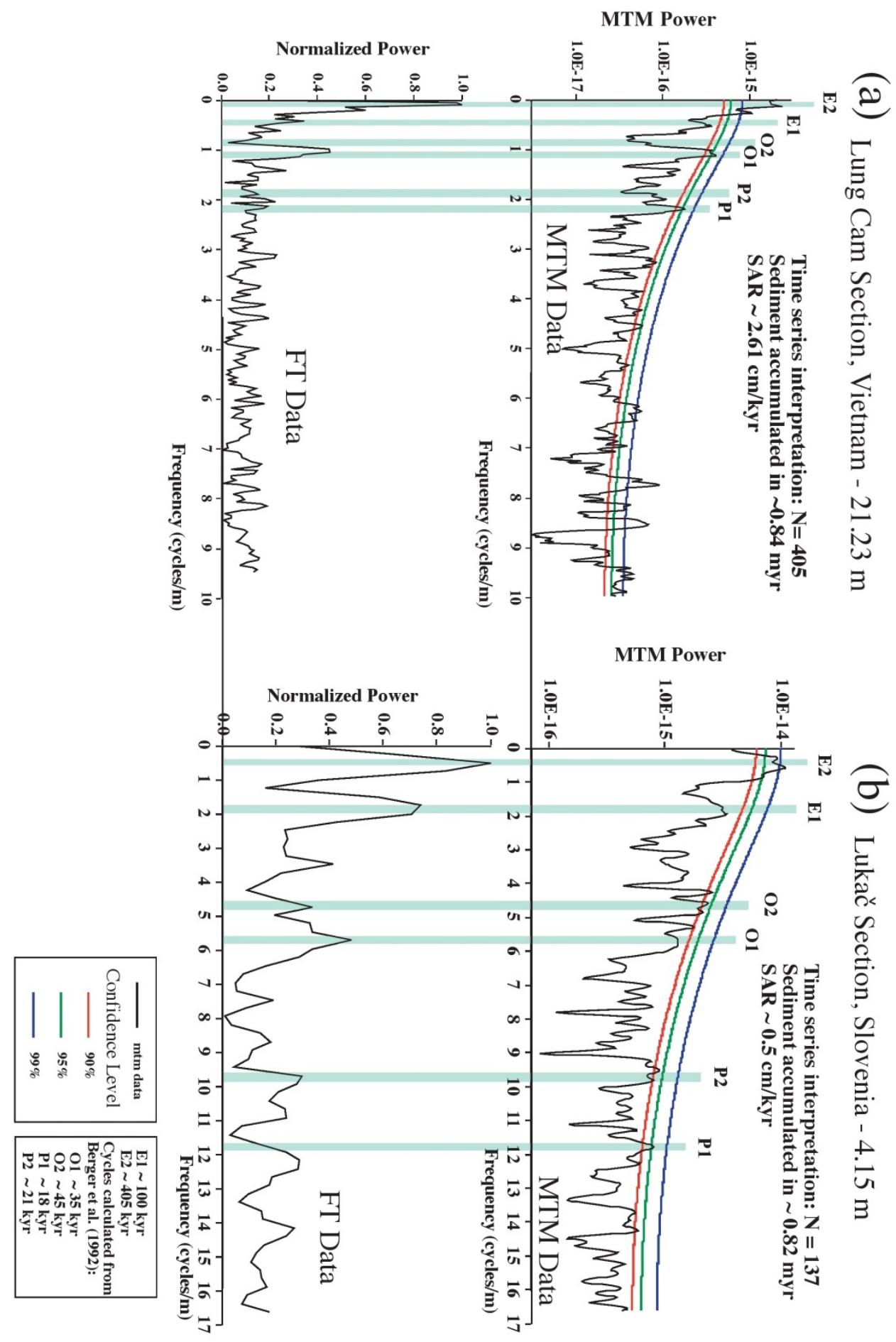

Figure 4. Time-series for (a) the Lung Cam $\chi$ data (Ellwood et al., 2017), and (b) the Lukač section. Time-series was performed on the raw $\chi$ data points presented in Figures 1 and 3 


\subsection{Graphic Comparison}

Graphic comparison was used to evaluate similarities between sections and climate models for P1 precession data presented in Figure 4a, which shows high P1 confidence for the Lung Cam data, and $\mathrm{O} 2$ obliquity data from Figure 4b, which shows high O2 confidence for the Lukač section. These data were used in developing floating-point time scales for Lung Cam and the Lukač sections (X axis in Figures 5 and 6). To do this, the bottoms and tops of the $\chi$ zones from each section analyzed were plotted against a uniform P1 climate model for the Lung Cam section (Figure 5 ), and the against a uniform $\mathrm{O} 2$ climate model for the Lukač section (Figure 6). Once these correlation points were established, a best-fit Line-of-Correlation (LOC) tunnel was fit to each data set through straight-line segments defined by the correlated data points. The process is similar to that developed by Shaw (1964) for Graphic Correlation.

\section{Graphic Comparison: Lung Cam $\chi$ Data to a Standard Precessional ( 18,000 year) Climate Model Covering $\sim 792$ kyr}

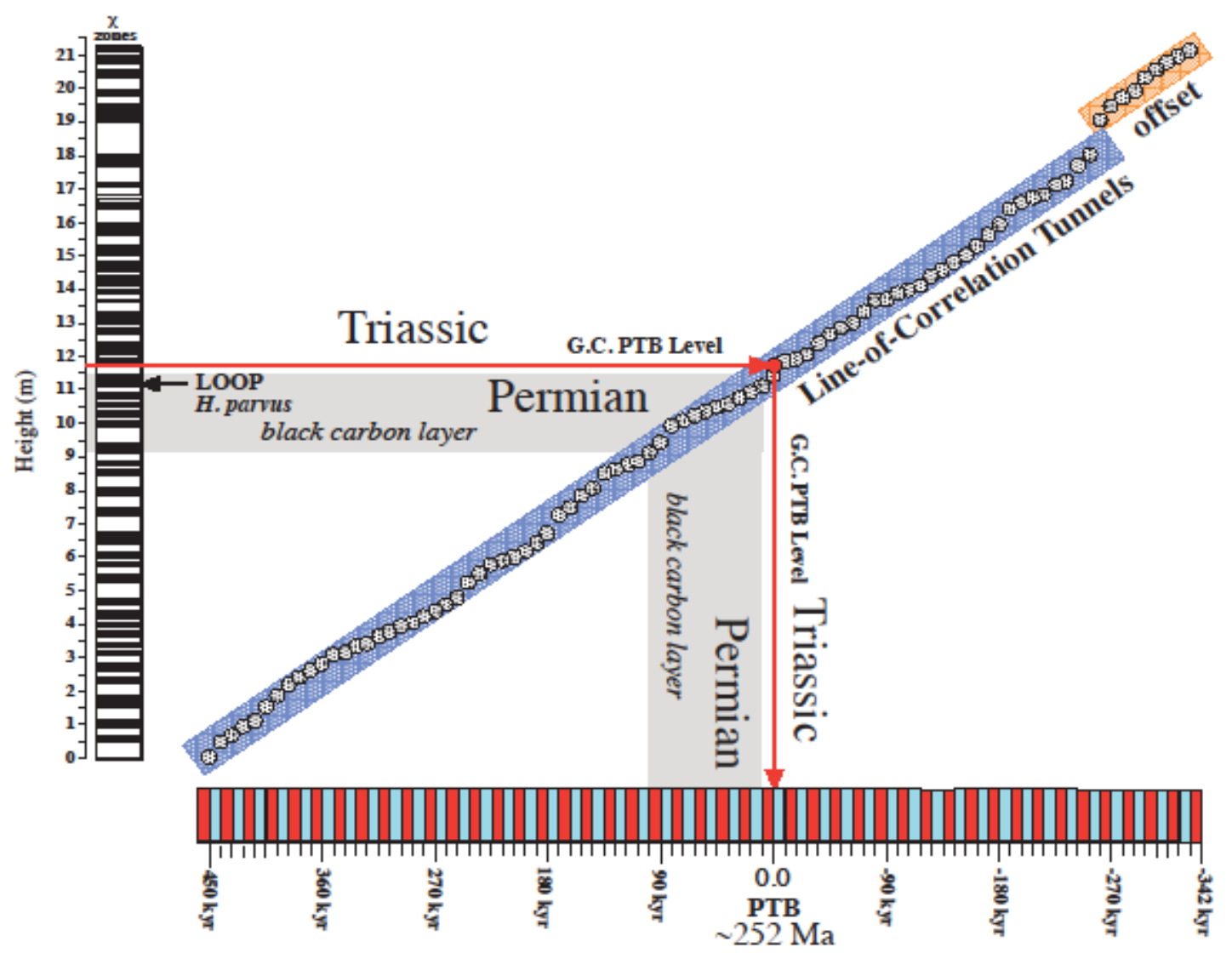

P1 Precession Floating-Point Time Scale Climate Model Centered on $252 \mathrm{Ma}$

Figure 5. Graphic comparison between the Lung Cam, Vietnam $\chi$ bar-log data and the P1 obliquity uniform timescale model for the Lung Cam PTB interval. Stippled dots represent the intersections between $\chi$ bar-log and P1 uniform zones. A Line-of-Correlation (LOC) tunnel is fit to the data with the exception of an offset at the top of the section, due to an anomalously low $\chi$ zone at that level. Also shown is the Black Carbon interval common to both sections and the LOOP of $H$. parvus 


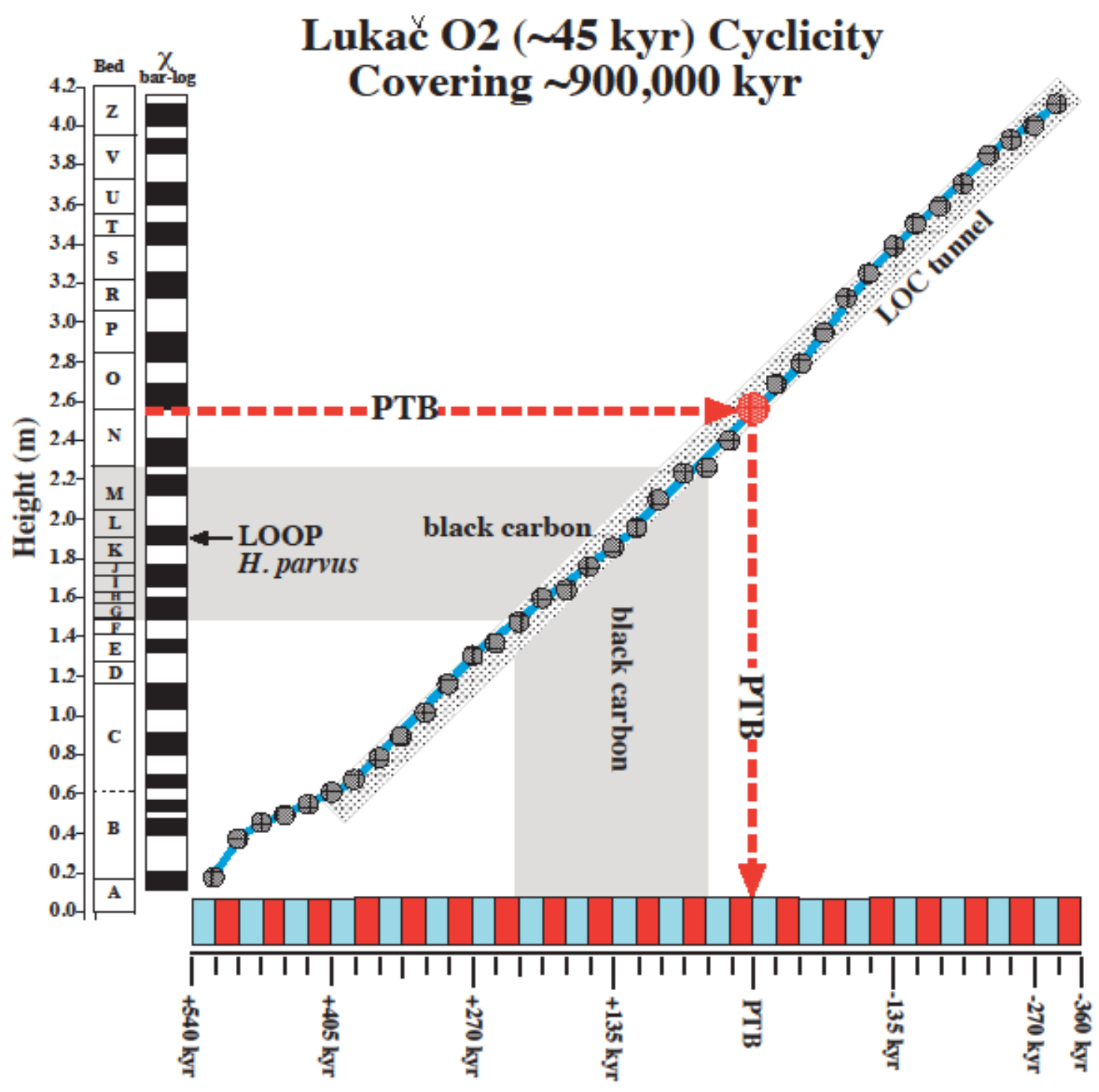

O2 ObliquityFloating-Point Time Scale Climate Model Centered on $252 \mathrm{Ma}$

Figure 6. Graphic comparison between the Lukač $\mathrm{O} 2 \chi$ bar-log data and an $\mathrm{O} 2$ obliquity uniform time-scale model for the PTB interval. Plot elements as in Figure 5. A Line-of-Correlation (LOC) tunnel is fit to the data with some deviation at the base of the section, due to an anomalously low $\chi$ zone at that level. Also shown is the Black Carbon interval common to both sections and the LOOP of $H$. parvus

\section{Results}

\subsection{Time-series analysis}

Time-series analyses for the Lung Cam, Vietnam and Lukač, Slovenia sections are presented in Figures 4a and 4b. Note that E2
(405 kyr) eccentricity, O1 ( 35 kyr) obliquity, and P1 ( 18 kyr) precession, have high MTM confidence for samples from Vietnam (eastern Paleo-Tethys; Figure 2), whereas E2, O2 ( 45 kyr) obliquity, and both P2 ( 21 kyr) and P1 precession have high MTM confidence for 
samples from Slovenia (western Paleo-Tethys; Figure 2). Obliquity and precession for the PTB have been calculated from values published by Berger et al. (1992). Using the time series data (Figure 4a and $4 \mathrm{~b}$ ), an SAR and length of time represented by each section was calculated: for Lung Cam, an SAR of $\sim 2.53 \mathrm{~cm} / \mathrm{kyr}$ (a relatively high marine rate) and duration of $\sim 0.84$ myr; for Lukač, an SAR of $\sim 0.51 \mathrm{~cm} / \mathrm{kyr}$ (more of a roughly average marine value) and duration of $\sim 0.82$ myr. Note that total time recorded is very similar between the two successions.

Note that the Ellwood et al. (2017) paper gave an approximate sediment SAR value for a graphically correlated Lung Cam data set to the Meishan GSSP only covering an interval of $\sim 2.8 \mathrm{~m}$ of section that allowed them to estimate an SAR value of $\sim 4.6 \mathrm{~cm} / \mathrm{kyr}$. However, in the current paper, using time-series analysis, the SAR was calculated as $\sim 2.53$ $\mathrm{cm} / \mathrm{kyr}$. This new value included the entire $21.23 \mathrm{~m}$ of section sampled. The difference between the values reported here, and those reported by Ellwood et al. (2017) can be accounted any of three possibilities: (1) 18.43 more meters of section are reported herein for the Lung Cam section; (2) there are fairly large uncertainties for an SAR in Graphic Correlation when the LOC is very steep, which is the case in the Ellwood et al. (2017) paper, thus only allowing "estimates" for the SAR; and (3) there may be unrecognized missing section that would reduce the overall SAR for the section reported herein. The timeseries analysis of a thick, densely sampled section, allows much better estimates of the total SAR for the section. We know of course that SARs can vary a lot throughout a period of $\sim 840,000$ years, and so in their 2017 paper, Ellwood et al. were looking at only $\sim 2.8 \mathrm{~m}$ of section, where uncertainties were large.

\subsection{Magnetic susceptibility $(\chi), \mathrm{SiO}_{2}$, and $\delta^{18} \mathrm{O}$ for the Lung Cam and Lukač sections}

The $\chi$, bar log cyclicity, lithology, $\mathrm{SiO}_{2}$, and $\delta^{18} \mathrm{O}$ data for the Lung Cam and Lukač sections are reported in Figures 1 and 3. Included in these diagrams is the PTB position in Lung Cam as the solid red line (Figure 1), determined using Graphic Correlation from Ellwood et al. (2017), and the projected PTB for the Lukač section (Figure 3) is correlated by graphic comparison of the $\chi$ data between the Lung Cam and Lukač sections as presented in Figure 7.

Figure 5 presents the Lung Cam section, Vietnam, uniform bar-log zonation for P1 precession cycles (the Y-axis in Figure 5 represents the high confidence peak P1 (Figure $4 a)$, representing $\sim 18 \mathrm{kyr}$ cyclicity) that is graphically correlated to the Lung Cam $\chi$ bar$\log$ zonation, where $\chi$ was adjusted by smoothing using splines to conform to the time-series results. The LOC for these two data sets (Figure 5) shows high consistency and exhibits longer-term cycles within the LOC tunnel. This Floating-point time-scale model, developed from time-series of the $\chi$ zonation, allows assignment of ages relative to the PTB. The length of time represented in Figure 5 is $\sim 792 \mathrm{kyr}$, but does not include the offset identified in Figure 5, that is caused by an unusually long, low $\chi$ interval existing between 18$19 \mathrm{~m}$ in the Lung Cam section.

Comparison between the Lukač section, Slovenia, and the high confidence $\mathrm{O} 2$ obliquity $\sim 45$ kyr cyclicity (Figure $4 b$ ), shows excellent correlation through most of the section with the uniform obliquity time scale model (Figure 6). The model, when compared with the PTB age assignment, shows that the Lukač section represents $\sim 900 \mathrm{kyr}$ of time. It is important to note that the boundary interval in 
both sections includes the Black Carbon found in agglutinated foraminifers (Ellwood et al., 2017 and related papers). The observed Black Carbon is interpreted to be the result of possible global fires that preceded the PTB, and clearly this interval is found throughout the Paleo-Tethys Ocean. These fires are thought to be possibly the result of Siberian Traps volcanic eruptions, where vast amounts of carbon from these fires were incorporated by agglutinated foraminifers into their tests (Ellwood et al., 2017 and referenced papers). Also observed in both sections are the occurrences of $H$. parvus, where the LOOP of $H$. parvus lies within the Black Carbon interval. These observations indicate that these two sections, Lung Cam and Lukač, overlap, and are similar in age and duration. Given that the equivalent sampled portions at Lung Cam represent $\sim 21.2 \mathrm{~m}$ of section and the Lukač section $\sim 4.2$ $\mathrm{m}$, the Lung Cam section is expanded by 5 times relative to the Lukač section. The expanded nature of the Lung Cam data set allows higher resolution for the Lung Cam data set.

In Figure $1, \delta^{18} \mathrm{O}$ data were calculated from 404 samples collected from Lung Cam. The $\delta^{18} \mathrm{O}$ data show trends within the section with values between -6 and $-12 \%$, with some apparent cyclicity, interpreted to be associated with climatic variations. Therefore, at the top of the $\delta^{18} \mathrm{O}$ column in Figure 1, a trend arrow is placed indicating warmer versus colder climate variations recorded in the section by the $\delta^{18} \mathrm{O}$ data. Independent negative $\delta^{18} \mathrm{O}$ shifts toward abrupt warming, of $>4 \%$, are identified between $\sim 3.0$ to $\sim 3.5 \mathrm{~m}, \sim 13.2$ and $\sim 13.5$ $\mathrm{m}$, and $\sim 17.0$ and $\sim 17.3 \mathrm{~m}$ height in the Lung Cam section (Figure 1), and labeled ' $\delta^{18} \mathrm{O}$ shift' in Figure 1. These $\delta^{18} \mathrm{O}$ shifts appear to be correlated to similar abrupt shifts in the Lukač section (Figure 3). There is one large anomalous set of values at Lung Cam (stippled in Figure 1) that at this stage in our research are still being investigated.

\subsection{Correlating Lung Cam and Lukač sec- tions}

Graphic Comparison is used in Figure 7 to correlate between the Lung Cam and Lukač sections. Note that bar-logs used herein for both sections are from the $\mathrm{O} 1$ obliquity results from Figure 4a and b. The $\mathrm{O} 1$ cyclicity was used for this comparison because the $\mathrm{O} 1$ data sets from Lung Cam and Lukač are the best fit climate cycles common to the two sections. Added to the $\chi$ bar-log comparisons from Figures 1 and 3, are ash beds physically identified and sampled at Lung Cam (Beds $-18,-4$, and 13, orange lines in Figure 7 ), and the same beds unrecognized in outcrop in the Lukač section, but fingerprinted using geochemical signatures $\left(\mathrm{SiO}_{2}\right.$ in Figures 1 and 3). Also shown are $\delta^{18} \mathrm{O}$ shifts identified in Figures 1 and 3, which appear to be correlated between the two sections (light blue lines in Figure 7). This correlation is expected because $\delta^{18} \mathrm{O}$ shifts variations represent global climate changes. The projected intersections of these $\delta^{18} \mathrm{O}$ and $\mathrm{SiO}_{2}$ peaks lie close to individual LOC segments and within the LOC Tunnel, although there is some systematic deviation. To characterize this observation, we have placed a second line of correlation (green LOC in Figure 7) drawn through the ash bed and isotopic points, which are well correlated up to and through the PTB point. The deviation of LOC segments within the LOC Tunnel is due to variability imposed on the data mainly by the E2 (405 kyr) eccentricity band (Figure $4 a$ and $b$ ).

The 'black carbon' interval seen in each section is also plotted in Figure 7. Whereas the intersection of the top of the Black Carbon interval falls within the LOC Tunnel, the base of the Black Carbon interval does not. This discrepancy suggests that the beginning of the deposition of the Black Carbon occurs earlier in the Lukač section than at Lung Cam, possibly due to environmental differences at that time between the two sections. 


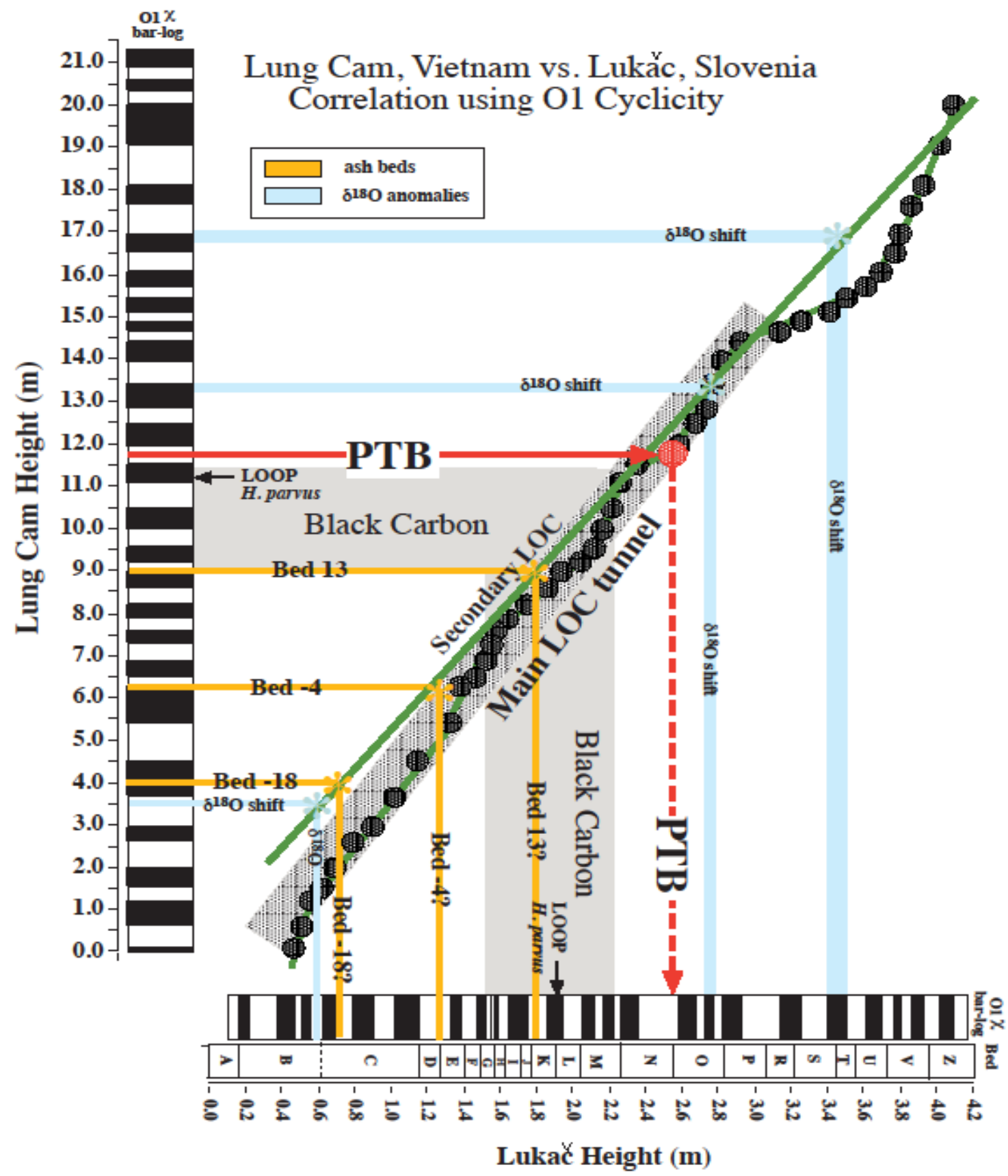

Figure 7. Graphic comparison diagram between the Lung Cam section, Vietnam, obliquity (O1) climate cycles, determined from $\chi$ cyclicity and time-series analysis (Figure 4a), and the Lukač section, Slovenia (Figure 4b). Shown is the Black Carbon interval common to both sections and the LOOP of $H$. parvus. A Line of Correlation (LOC) Tunnel (dashed fill) is fit to the cyclicity data. The green secondary LOC is drawn through the ash beds and $\delta{ }^{18} \mathrm{O}$ peaks that appear to be common to both sections. The range of the PTB interval for the Lukač section is based on the projection of the PTB in the Lung Cam section that is projected to the Main LOC tunnel and the secondary LOC. The Lukač section PTB is based on an oval through the main LOC tunnel that is then projected into the Lukač section, providing uncertainties for the PTB pick in the Lukač section 


\section{Discussions}

Isotopic studies of marine sediments/rocks rely on the assumption that isotopic (and cyclic lithologic) changes are a proxy for climate cycles that are assumed to be global (i.e., Imbrie et al., 1984; Dinarès-Turell et al., 2007). Tests of these hypotheses have shown that time-series data can provide a much higher resolution for time scales than are available using only biostratigraphic information. Such data sets have not been documented for most of the Phanerozoic, however, because stratigraphic sequences are imperfect recorders of time due to erosion, non-deposition, bioturbation, alteration and other processes. As a consequence of these processes, short-term Milankovitch bands (Earth's obliquity and precession) are not as well developed in older rocks as they are in younger sequences. However, it is now clear that time-series analysis of cyclic geophysical (i.e., $\chi$ and gamma ray spectroscopy; Ellwood et al., 2013; 2017) and geochemical data sets are controlled by global processes driven by climate.

It is well established that $\chi$ data sets in both unlithified and lithified marine sediments can be used to track climate cyclicity. Therefore, the cyclostratigraphy recorded in these sequences can be used for calibration of geologic time scales (Mead et al., 1986; Hartl et al., 1995; Weedon et al., 1997; Shackleton et al., 1999; Weedon et al., 1999). In addition to its utility in paleoclimatic studies, magnetostratigraphic susceptibility (Salvador, 1994) can be used for high-resolution correlation among marine sedimentary rocks of broadly differing facies with regional and global extent (Whalen and Day, 2008). $\chi$, when used as a correlation tool, provides a robust data set to independently evaluate and adjust stratigraphic position among geological sequences. Reasonable biostratigraphic control is required to initially develop a chronostratigraphic framework where distinctive $\chi$ zones can be directly correlated with high precision among succes- sions, even when biostratigraphic uncertainties or slight unconformities are known to exist within sections (Ellwood et al., 2006). The method is particularly useful for independent age control because it can extract data from sections that are not amenable to other magnetostratigraphic techniques, such as remnant magnetization (Berggren et al., 1995; Gradstein et al., 2004), because $\chi$ does not require that the rock or sediment analyzed be oriented. $\chi$ works as a climate proxy because regional and global processes that drive erosion, including climate and eustasy, bring the detrital components responsible for the $\chi$ signature into the marine environment where its stratigraphy is preserved.

Because $\chi$ zones have been shown to represent Milankovitch climate cyclicity, $\chi$ data sets can also be considered as floating-point time scales, with each $\chi$ zone representing a Milankovitch half cycle (e.g., Figure 1). Then, depending on the absolute time scale used, it is possible to assign specific relative ages to each $\chi$ zone boundary and thus to estimate the timing of any biostratigraphic zonation used, bioevents identified in the sequence, overall time represented by the section, and sediment accumulation rates.

To plug into a specific time scale, an absolute age must be used. If the time scale used is different or changes, for example, if the decay constants are redefined, then it is a simple matter to recalculate the new relative age of the $\chi$ zone of interest. Timing of these zones can then be compared on a global scale to other sections using the $\chi$ zonation identified for those sequences, and high-resolution timeseries ages can then be calculated.

The Lung Cam section in Vietnam is an expanded succession, where $\sim 800 \mathrm{kyr}$ of recorded time through the PTB interval is exposed over $21 \mathrm{~m}$ of section (Figure 1 ). Given that Lung Cam is well correlated to the GSSP (Ellwood et al., 2017 and referenced papers), it provides an excellent proxy to which other 
PTB sections can be compared. Herein, we use geophysical, geochemical and biostratigraphic information to correlate between two PTB successions, the Lung Cam section, Vietnam, and the Lukač section in Slovenia (Ellwood et al., 2017 and related papers.). These sequences were deposited at opposite ends of the Paleo-Tethys Ocean, but at similar latitudes (Figure 2), and the results presented here provide unprecedented, high-resolution timing, time-series dates and comparisons for both successions (Figures 1 and 3 ).

The two PTB successions studied are shown to be well-correlated using conodont biostratigraphy and $\chi$ bar-log graphic correlation in conjunction with unique correlated ash beds, black carbon in agglutinated foraminifers (Ellwood et al., 2017 and related papers), and $\delta^{18} \mathrm{O}$ shifts showing approximately the same magnitude of change. Using time-series analysis for each of these successions, relative to the PTB, high-resolution ages for event horizons in both successions were developed. As noted above, although the Lung Cam and Lukač successions were deposited at opposite ends of the Paleo-Tethys Ocean, it is clear that the processes identified and dated herein are essentially global. These data argue that, as is also the case for the modern Earth, where low-latitude dust from the Sahara Desert is distributed across the Atlantic Ocean in North America, and from Asia widely across the Pacific Ocean (Balsam et al., 1995; 2007), so also during PTB time, volcanic dust (ash) was deposited throughout the Paleo-Tethys area, and this ash provides marker horizons that contribute to data sets used for high-resolution correlation and timing.

Given that excellent correlation has been demonstrated for the Lung Cam and Lukac successions, then oceanographic differences within the Paleo-Tethys Ocean can be characterized. For example, whereas $\delta^{18} \mathrm{O}$ ranges are similar between the two sites (Figures 1 and 3 ), the trend in climate below the boundary is different between the two localities, where $\delta^{18} \mathrm{O}$ values appear to reflect colder temperatures in Slovenia, located along the western margin of the Paleo-Tethys Ocean at that time. If colder, then this change is probably associated with enhanced glaciation at that time, driving sea-level and base-level change, thus yielding enhanced erosion that is reflected in increased $\chi$ values. In the east in Vietnam, in the latest Permian, temperatures appear to have been generally warmer. However, above the PTB in the Triassic, climate appears to be similar and generally warmer in both areas (Figures 1 and 3). The change toward warmer climate happens in the Lukač section at the base of the Black Carbon interval, whereas in the east at the base of the Black Carbon interval in the Lung Cam section there is a change toward a cooler climate that ends at the top of the Black Carbon interval.

Another similarity in the two data sets is a lithologic change in the limestone beds in both sections, where in the Lung Cam section, $\sim 2.5 \mathrm{~m}$ below the PTB, the section contains minor ankeritic and sideritic mineralization, indicating a more reducing environment during this time (Figure 1). This chemical reduction begins immediately after a significant ash bed appears in the bed at $\sim 9 \mathrm{~m}$ in the section. There is a similar change in the Lukač section at $\sim 2.0 \mathrm{~m}$ in the section and up to the PTB, where minor dolomitic/ankeritic/sideritic mineralization occurs (Figure 3), again suggesting a change toward a more reducing environment.

To produce high-resolution time scales for both the Lung Cam and Lukač sections, we have used graphic correlation between the $\chi$ zonation for each section (Figures 1 and 3 ) and precessional and obliquity climate cyclicities for the two successions sampled and measured. For the Lung Cam data set, the $\chi$ zonation for the $\mathrm{P} 1$ precessional cyclicity was compared graphically to the P1, $18 \mathrm{kyr}$ uni- 
form floating-point time-scale climate model centered on the PTB, with an age assignment of $\sim 252$ Ma (Figure 5). The results define an excellent Line-of-Correlation (LOC) tunnel containing a slight but relatively uniform cyclicity that appears to represent eccentricity variations in the data set, as well as some noise. At $\sim 18 \mathrm{~m}$ height in the section there is an offset that is interpreted to represent a missing $\chi$ zone at that level in the section, possibly the result of local alteration or bioturbation. Figure 5 provides a time-series floating-point time-scale for the Lung Cam section, ranging from $\sim 450 \mathrm{kyr}$ below the PTB, through the PTB and to $342 \mathrm{kyr}$ above the PTB, if the offset is included. This result means that each black or white segment of the $\chi$ zonation represents $\sim 9 \mathrm{kyr}$. Therefore, the LOOP of $H$. parvus shown in Figure 5, arrived at Lung Cam $\sim 9$ kyr before the PTB, indicating that $H$. parvus arrived at Lung Cam before arriving at the GSSP in Meishan, China.

For the time-series analysis for the Lukač section, the $\chi$ zonation was graphically correlated to an $\mathrm{O} 2$ obliquity uniform climate model, plotted relative to the PTB level extrapolated for the section (Figure 6). In this case, the section ranges from $\sim 517.5 \mathrm{kyr}$ below the PTB at $252 \mathrm{Ma}$, to $320 \mathrm{kyr}$ above the PTB, a range of $\sim 840 \mathrm{kyr}$. Therefore, each black or white segment of the $\chi$ zonation represents $\sim 22.5$ kyr. This timing can then be applied directly to each $\chi$ zone in the Lukač section. Therefore, when the LOOP of $H$. parvus, shown in Figure 6, is projected through the LOC in Figure 6, and into the floating-point time-scale, the result indicates that $H$. parvus arrived at the Lukač section $\sim 128 \mathrm{kyr}$ before the PTB, well before it arrived at either Lung Cam in Vietnam or the GSSP in Meishan, China. This result suggests that $H$. parvus appeared first along the western margin of the Paleo-Tethys Ocean and much later along the eastern margin.
In an effort to directly correlate the $\chi$ zonations for both sections (Figure 7), it was necessary to use the same climate cyclicity for both data sets. For this purpose we chose the O1 obliquity zonation that is fairly well defined in both studied sections in the FT data sets (Figure 4). In Figure 7, there is a welldefined LOC tunnel from the base of both sections and up to $\sim 14.5 \mathrm{~m}$ in the Lung Cam section, and to $\sim 3.2 \mathrm{~m}$ in the Lukač section. Given that the PTB is well defined in the Lung Cam section (Ellwood et al., 2017 and referenced papers), we used the PTB position in Lung Cam as the PTB standard, and extrapolated that position from the Lung Cam section through the LOC in Figure 7, and down into the Lukač section. The oval of uncertainty defined by the width of the LOC tunnel provides the uncertainty presented. Correlated in Figure 7 from both sections are the $\mathrm{SiO}_{2}$ ash bed levels and the $\delta^{18} \mathrm{O}$ shifts. Graphic correlation of these two data sets from each section provided a secondary LOC that correlates well with the PTB pick for the Lukač section. Also shown are the Black Carbon zones from both sections, where agglutinated foraminifers have fixed elemental carbon in their tests (Figure 7).

\section{Conclusions}

Magnetic susceptibility $\chi$ correlations among two Permian-Triassic boundary (PTB) successions, one at Lung Cam in Vietnam on the eastern margin of the Paleo-Tethys Ocean, and the second, Lukač in Slovenia on the western margin of the Paleo-Tethys Ocean, and at similar paleolatitudes, show the following similar trends: (a) time covered by deposited, mainly limestone sediment; (b) presence below the PTB of the Lowest Observed Occurrence Point (LOOP) of Hindeodus parvus, the boundary-defining fossil at Meishan, the Global Boundary Stratotype Section and Point (GSSP) in China; (c) Black Carbon levels below the PTB, where agglutinated foraminifers 
have incorporated carbon into their tests, possibly from fires generated globally by Siberian Traps eruptions; (d) systematic time-series analyses results that can be modeled by uniform floating-point time-scale climate models centered on the PTB at 252 Ma; (e) wellconstrained Lines-of-Correlation (LOC)s for most of the intervals sampled; and (f) excellent correlation when $\chi$ data are directly compared.

Ash beds and $\delta^{18} \mathrm{O}$ abrupt shifts that appear to be common to both the Lung Cam and Lukač sections are useful in correlating among the two successions, indicating that ash, like dust from the Sahara, can be blown over long distances and provide marker horizons for correlation.

$\delta^{18} \mathrm{O}$ data for the two sections indicate that in the western Paleo-Tethys area below the PTB, climate was generally colder in Slovenia than in Vietnam, at least up to the time when the Black Carbon was deposited. Immediately after that time, climate became colder in Vietnam, and warmer in Slovenia. The observed $\delta^{18} \mathrm{O}$ shifts represent some striking examples of abrupt, but short warming climate pulses at both localities.

The graphic correlation data, along with occurrences in both sections of $H$. parvus, indicate that $H$. parvus arrived at the Lukač area $\sim 128 \mathrm{kyr}$ before it arrived at the Meishan PTB GSSP area in China. In addition, $H$. parvus arrived at the Lung Cam area $\sim 9 \mathrm{kyr}$ before arrival at Meishan.

\section{Acknowledgements}

This work was partly supported by the National Science Foundation, (grant number EAR-0745393 to BBE), by the Vietnamese Academy for Science and Technology (VAST05.03/17-18), and the Robey Clark endowment to LSU. We thank Sue Ellwood for designing the sample method used and her aid in sampling. Samples in Lukač were collected with the help of Tea Kolar-Jurkovšek. We thank C. Scotese for his help in designing Figure 2.

\section{References}

Balsam W., Arimoto R., Ji J., Shen Z, 2007. Aeolian dust in sediment: a re-examination of methods for identification and dispersal assessed by diffuse reflectance spectrophotometry. International Journal of Environment and Health, 1, 374-402.

Balsam W.L., Otto-Bliesner B.L., Deaton B.C., 1995. Modern and last glacial maximum eolian sedimentation patterns in the Atlantic Ocean interpreted from sediment iron oxide content. Paleoceanography, 10, 493-507.

Berggren W.A., Kent D.V., Aubry M-P., Hardenbol J., 1995. Geochronology, Time Scales and Global Stratigraphic Correlation. SEPM Special Publication \#54, Society for Sedimentary Geology, Tulsa, OK, 386p.

Berger A., Loutre M.F., Laskar J., 1992. Stability of the astronomical frequencies over the Earth's history for paleoclimate studies. Science, 255, 560-566.

Bloemendal J., deMenocal P., 1989. Evidence for a change in the periodicity of tropical climate cycles at 2.4 Myr from whole-core magnetic susceptibility measurements. Nature, 342, 897-900.

Chen J., Shen S-j., Li X-h., Xu Y-g., Joachimski M.M., Bowring S.A., Erwin D.H., Yuan D-X., Chen B., Zhang H., Wang Y., Cao C-q, Zheng Q-f., Mu L., 2016. High-resolution SIMS oxygen isotope analysis on conodont apatite from South China and implications for the end-Permian mass extinction. Palaeogeography, Palaeoclimatology, Palaeoecology, 448, 26-38.

Da Silva A-C., Boulvain F., 2002. Sedimentology, magnetic susceptibility and isotopes of a Middle Frasnian carbonate platform: Tailfer Section, Belgium. Facies, 46, 89-102.

Da Silva A.-C., Boulvain F., 2005. Upper Devonian carbonate platform correlations and sea level variations recorded in magnetic susceptibility. Palaeogeography, Palaeoclimatology, Palaeoecology, 240, 373-388.

Dettinger M.D., Ghil M., Strong C.M., Weibel W., Yiou P., 1995. Software expedites singular-spectrum 
analysis of noisy time series. EOS. Transactions of the American Geophysical Union, 76, 12-21.

Dinarès-Turell J., Baceta J.I., Bernaola G., OrueEtxebarria X., Pujalte V., 2007. Closing the MidPalaeocene gap: Toward a complete astronomically tuned Palaeocene Epoch and Selandian and Thanetian GSSPs at Zumaia (Basque Basin, W Pyrenees). Earth Planetary Science Letters, 262, 450-467.

Ellwood B.B., García-Alcalde J.L., El Hassani A., Hladil J., Soto F.M., Truyóls-Massoni M., Weddige K., Koptikova L., 2006. Stratigraphy of the Middle Devonian Boundary: Formal Definition of the Susceptibility Magnetostratotype in Germany with comparisons to Sections in the Czech Republic, Morocco and Spain. Tectonophysics, 418, 31-49.

Ellwood B.B., Wang W.-H., Tomkin J.H., Ratcliffe K.T., El Hassani A., Wright A.M., 2013. Testing high resolution magnetic susceptibility and gamma gradiation methods in the Cenomanian-Turonian (Upper Cretaceous) GSSP and near-by coeval section. Palaeogeography, Palaeoclimatology, Palaeoecology, 378, 75-90.

Ellwood B.B., Wardlaw B.R., Nestell M.K., Nestell G.P., Luu Thi Phuong Lan, 2017. Identifying globally synchronous Permian-Triassic boundary levels in successions in China and Vietnam using Graphic Correlation. Palaeogeography, Palaeoclimatology, Palaeoecology, 485, 561-571.

Ghil M., Allen R.M., Dettinger M.D., Ide K., Kondrashov D., Mann M.E., Robertson A., Saunders A., Tian Y., Varadi F., Yiou P., 2002. Advanced spectral methods for climatic time series. Reviews of Geophysics, 40, 3.1-3.41. http://dx.doi.org/10.1029/2000RG000092.

Gradstein F.M., Ogg J.G., Smith A.G., 2004. A geologic Time Scale 2004. Cambridge University Press, England, 589p.

Hartl P., Tauxe L., Herbert T., 1995. Earliest Oligocene increase in South Atlantic productivity as interpreted from "rock magnetics” at Deep Sea drilling Site 522. Paleoceanography, 10, 311-326.

Imbrie J., Hays J.D., Martinson D.G., McIntyre A., Mix A.C., Morley J.J., Pisias N.G., Prell W.L., Shackleton N.J., 1984. The Orbital Theory of Pleistocene
Climate: Support from a Revised Chronology of the Marine Delta ${ }^{18} \mathrm{O}$ Record. In Berger A.L., Imbrie J., Hays J., Kukla G., Saltzman B. (Eds.), Milankovitch and Climate, Part I, Kluwer Academic Publishers, 269-305.

Mead G.A., Yauxe L., LaBrecque J.L., 1986. Oligocene paleoceanography of the South Atlantic: paleoclimate implications of sediment accumulation rates and magnetic susceptibility. Paleoceanography, 1, 273-284.

Salvador A. (Ed.), 1994. International Stratigraphic Guide: The International Union of Geological Sciences and The Geological Society of America, Inc., $2^{\text {nd }}$ Edition, 214p.

Scotese C.R., 2001. Atlas of Earth History, Volume 1, Paleogeography, PALEOMAP Project, Arlington, Texas, 52p.

Scotese C.R., 2013. Map Folio 49, Permo-Triassic Boundary (251 Ma), PALEOMAP PaleoAtlas for ArcGIS, Triassic and Jurassic Paleogeographic, Paleoclimatic and Plate Tectonic Reconstructions, PALEOMAP Project, Evanston, IL, 3.

Shackleton N.J., Crowhurst S.J., Weedon G.P., Laskar J., 1999. Astronomical calibration of OligoceneMiocene time. Philosophical Transactions of the Royal Society London, A357, 1907-1929.

Shaw A.B., 1964. Time in Stratigraphy. New York, Mc Graw Hill, 365p.

Shen S.-Z., Crowley J.L., Wang Y., Bowring S.A., Erwin D.H., Henderson C.M., Ramezani J., Zhang H., Shen Y.,Wang X.-D., Wang W., Mu L., Li W.-Z., Tang Y.-G., Liu X.-L., Liu X.-L., Zeng Y., Jiang Y.F., Jin Y.-G., 2011a. High-precision geochronologic dating constrains probable causes of Earth's largest mass extinction. Science, 334, 1367-1372. Doi:10.1126/science.1213454.

Swartzendruber L.J., 1992. Properties, units and constants in magnetism. Journal of Magnetic Materials, 100, 573-575.

Weedon G.P., Jenkyns H.C., Coe A.L., Hesselbo S.P., 1999. Astronomical calibration of the Jurassic timescale from cyclostratigraphy in British mudrock formations. Philosophical Transactions of the Royal Society London, A357, 1787-1813. 
Luu Thi Phuong Lan, et al./Vietnam Journal of Earth Sciences 40 (2018)

Weedon G.P., Shackleton N.J., Pearson P.N., 1997. The Oligocne time scale and cyclostratigraphy on the Ceara Rise, western equatorial Atlantic. In: Schackleton N.J., Curry W.B., Richter C., and Bralower T.J. (Eds.). Proceedings of the Ocean Drilling Program, Scientific Results, 154, 101-114.
Whalen M.T., Day J.E., 2008. Magnetic Susceptibility, Biostratigraphy, and Sequence Stratigraphy: Insights into Devonian Carbonate Platform Development and Basin Infilling, Western Alberta. Papers on Phanerozoic Reef Carbonates in Honor of Wolfgang Schlager. SEPM (Society for Sedimentary Geology) Special Publication, 89, 291-314. 